\title{
CAUSES OF VISUAL HANDICAP AMONGST PATIENTS ATTENDING OUTPATIENT DEPARTMENT OF A TERTIARY CARE CENTER FOR VISUAL HANDICAP CERTIFICATE
}

\section{Dr Bhavika Patel}

\section{Dr. Wilhemina Asari}

\section{Dr. Chandni Sinojia*}

\author{
MS Ophthalmology, Tejas eye hospital, Mandavi,
} Assistant professor, M \& J Western regional institute of ophthalmology, Ahmedabad,

MS Ophthalmology, Senior resident, M \& J Western regional institute of ophthalmology, Ahmedabad, * Corresponding Author

ABSTRACT

PURPOSE- To analyse various ocular diseases leading to permanent visual handicap in a district based on visual handicap certification issued by ophthalmologist at tertiary care center after verification of the domicile of the person. METHOD - This is a retrospective analysis of patients attending outpatient department of tertiary care center for visual handicap certification. It was done over the period of one year with total recruitment of 311 patients. All patients were examined for best corrected visual acuity according to Snellen's chart, anterior and posterior segment examination. Ultrasonography and/or Optical Coherence Tomography and/or electroretinography / visual evoked potential was done in selected cases. After diagnosis, percentage of blindness was determined according to the categories of visual disability and blindness certificate was issued. RESULT- Maximum of the certified visually disabled individuals are of $21-30$ years (73 patients, 23.47\%). 212 patients were males and 99 were females. Visual disability of $100 \%$ was seen in 258 cases. Retinitis Pigmentosa was the most common cause seen in $67(21.54 \%)$ cases. Other major causes include congenital ocular malformation(16.40\%) optic atrophy(13.83\%), phthisis bulbi (8.68\%), corneal opacities(8.36\%), glaucoma(6.75\%). CONCLUSION- The burden of the blindness can be decreased by public education and genetic counselling regarding common and preventable causes of blindness, as early diagnosis, treatment and visual rehabilitation can help to improve visual outcome and ultimately visual handicap in the society for the better future.

\section{KEYWORDS :}

\section{INTRODUCTION}

"Blindness" means any of the following after best correction, either total absence of sight; or visual acuity less than $3 / 60$ or less than 10/200 (Snellen) in the best eye with best possible correction; or limitation of the field of vision subtending an angle of less than 10 degree. "Low vision" means a condition where a person has any of the following conditions, either visual acuity not exceeding $6 / 18$ or less than $20 / 60$ upto $3 / 60$ or upto 10/200 (Snellen) in the better eye with best possible correction; or limitation of the field of vision subtending an angle of less than 40 degree upto 10 degree ${ }^{1}$.

An estimated 285 million people worldwide live with vision impairment: 39 million are blind and 216 million have moderate to severe vision impairment. About 90 percent of them are living in developing countries ${ }^{2}$.

According to recent estimates by WHO, the major global causes of moderate to severe vision impairment are $^{3}$ : uncorrected refractive errors $53 \%$, cataract $25 \%$, age-related macular degeneration $4 \%$, glaucoma $2 \%$, diabetic retinopathy $1 \%$. The major causes of blindness are: cataract $35 \%$, uncorrected refractive error $21 \%$, glaucoma $8 \%$. Leading causes of childhood blindness include xerophthalmia, congenital cataract, congenital glaucoma and optic atrophy due to meningitis, retinopathy of prematurity and uncorrected refractive errors. Xerophthalmia is largely under control with vitamin A distribution in immunisation programmes ${ }^{4}$.

An estimated 19 million children are visually impaired. Of these, 12 million children have vision impairment due to refractive error. Around 1.4 million have irreversible blindness, requiring access to vision rehabilitation services to optimize functioning and reduce disability ${ }^{4}$.

The estimated number of visual disability in India according to the census 2011 is 50 lakhs $^{5}$. The 58th round data from the National Sample Survey Organization (NSSO), 2006-07 revealed that out of all the disabled individuals in India, $10.88 \%$ were blind and that $4.39 \%$ had low vision. Causes of blindness in India according to 2006-07 National survey on blindness are: Cataract $62.6 \%$, Refractive error $19.7 \%$, Glaucoma 5.8\%, Posterior segment pathology $4.7 \%$, Corneal opacity $0.9 \%$, Other causes $4.19 \%$, Surgical complications $1.2 \%$, Posterior capsular opacification $0.9 \%$.

Overall, the prevalence of vision impairment worldwide has decreased since 1990s due to socioeconomic development, concerted public health action, increased availability of eye care services and awareness of the general population about solutions of vision impairment (surgery, refraction devices etc). However it is estimated that the number of people with vision impairment could triple due to population growth and ageing. For example, by 2050 there could be 115 million people who are blind, up from 38.5 million in $2020^{3}$.

Blindness is a major public health problem in developing countries like India. It has multidimensional implications on a person's quality of life with immediate and long-term consequences in all age groups resulting in impaired physical, psychological, educational and economic growth. Persons having legal blindness can be placed on the blind register if they want, after having a certification of the ophthalmologist which can help them in availing various benefits offered by various schemes run by government such as scholarship schemes for students, concession in railway fare, rebate in income tax, reservation in government jobs, free travel in state transport buses, loan for starting own business, subsidized prosthetic aids and assistive devices, group insurance for government employees with disabilities, unemployment allowance to educated disabled persons, etc.

Percentage of visual handicap is accorded as proposed by the Ministry of Social Justice and Empowerment. According to these guidelines the minimum degree of disability should be at least $40 \%$ for an individual to be eligible for any concessions or benefit.

The prevention of visual impairment and blindness is a priority, and its planning requires data regarding its incidence and causes. 
AIM

- To analyse various ocular diseases leading to permanent visual handicap in Ahmedabad district situated in western India based on visual handicap certification issued by ophthalmologist at regional institute of ophthalmology after verification of the domicile of the person.

- To assess age-wise and gender distribution in these patients.

\section{MATERIALS AND METHOD}

Retrospective analysis of patients attending outpatient department of M \& J Institute of Ophthalmology, civil hospital, Ahmedabad for visual handicap certification during one period was done. Total 311 patients were recruited in the study. Inclusion criteria are:

- Subjects of all age groups and both the sexes with visual disability of $40 \%$ and above

- Patients having domicile in Ahmedabad district

\section{Exclusion criteria are:}

- Patients with visual disability of less than $40 \%$

- Patients having domicile outside the Ahmedabad district.

Routinely, data of the patients getting blindness certificates in the institute regarding name, age/sex of the patients, registration number, address, cause of blindness and percentage of the blindness is registered in the blindness register of the institute.

A specially designed proforma was used to record patient history, clinical examination details like visual acuity by Snellen's chart (5 years and above), slit-lamp examination of anterior segment, fundus examination by indirect ophthalmoscopy and recording of intraocular pressure. Patient's demographic details such as age, sex and causes for decreased vision/blindness were ascertained.

All patients underwent complete ophthalmologic evaluation as below:

- Best corrected visual acuity according to snellen's chart.

- Anterior segment examination using slit lamp.

- Posterior segment analysis by direct ophthalmoscope, indirect ophthalmoscope and/or slit lamp biomicroscopy using $+78 \mathrm{D}$ lens after dilating the pupil with mydriatic.

- Ultrasonography (USG) and/or Optical Coherence Tomography (OCT) and/or ERG/VEP in selected cases.

Each case was examined by the consultant ophthalmologist. Diagnosis was mentioned, percentage of blindness was determined according to the categories of visual disability according to guidelines of the Ministry of Social Justice and Empowerment, Government of India[Table 1] and blindness certificate was issued.

Table 1

\begin{tabular}{|c|c|c|c|}
\hline $\begin{array}{c}\text { Better eye best } \\
\text { corrected }\end{array}$ & $\begin{array}{c}\text { Worse eye best } \\
\text { corrected }\end{array}$ & \begin{tabular}{|l|} 
Percentage \\
impairment
\end{tabular} & $\begin{array}{l}\text { Disability } \\
\text { category }\end{array}$ \\
\hline \multirow[t]{4}{*}{$6 / 6$ to $6 / 18$} & $6 / 6$ to $6 / 18$ & $0 \%$ & 0 \\
\hline & $6 / 24$ to $6 / 60$ & $10 \%$ & 0 \\
\hline & $\begin{array}{l}\text { Less than } 6 / 60 \text { to } \\
3 / 60\end{array}$ & $20 \%$ & 1 \\
\hline & $\begin{array}{c}\text { Less than } 3 / 60 \text { to } \\
\text { no light } \\
\text { perception }\end{array}$ & $30 \%$ & $\begin{array}{c}2 \text { (one eyed } \\
\text { person) }\end{array}$ \\
\hline \multirow{3}{*}{$\begin{array}{c}6 / 24 \text { to } 6 / 60 \text { or } \\
\text { visual field less } \\
\text { than } 40 \text { upto } 20 \\
\text { degree around } \\
\text { center of fixation } \\
\text { or hemianopia } \\
\text { involving macula }\end{array}$} & $6 / 24$ to $6 / 60$ & $40 \%$ & $\begin{array}{l}3 a \text { (low } \\
\text { vision) }\end{array}$ \\
\hline & \begin{tabular}{|c|} 
Less than $6 / 60$ to \\
$3 / 60$ \\
\end{tabular} & $50 \%$ & $\begin{array}{l}3 \mathrm{~b} \text { (low } \\
\text { vision) }\end{array}$ \\
\hline & $\begin{array}{c}\text { Less than } 3 / 60 \text { to } \\
\text { no light } \\
\text { perception } \\
\end{array}$ & $60 \%$ & $\begin{array}{l}3 c \text { (low } \\
\text { vision) }\end{array}$ \\
\hline
\end{tabular}

\begin{tabular}{c|c|c|c|}
\hline $\begin{array}{c}\text { Less than } 6 / 60 \text { to } \\
3 / 60\end{array}$ & $\begin{array}{c}\text { Less than 6/60 to } \\
3 / 60\end{array}$ & $70 \%$ & $\begin{array}{c}3 \mathrm{~d} \text { (low } \\
\text { vision) }\end{array}$ \\
\cline { 2 - 4 } $\begin{array}{c}\text { Or visual field less } \\
\text { than } 20 \text { degree upto } \\
10 \text { degree around } \\
\text { center of fixation }\end{array}$ & $\begin{array}{c}\text { Less than } 3 / 60 \text { to } \\
\text { no light perception }\end{array}$ & $80 \%$ & $\begin{array}{c}3 \mathrm{e} \text { (low } \\
\text { vision) }\end{array}$ \\
\hline $\begin{array}{c}\text { Less than } 3 / 60 \text { to } \\
1 / 60\end{array}$ & $\begin{array}{c}\text { Less than } 3 / 60 \text { to } \\
\text { no light perception } \\
\text { visual field less } \\
\text { than } 10 \text { degree } \\
\text { around center of } \\
\text { fixation }\end{array}$ & $90 \%$ & $\begin{array}{c}4 a \\
\text { (blindness) }\end{array}$ \\
\hline $\begin{array}{c}\text { Only HMC(hand } \\
\text { movement close to } \\
\text { face), } \\
\text { Only light } \\
\text { perception, No light } \\
\text { perception }\end{array}$ & $\begin{array}{c}\text { Only HMCF, Only perception, No } \\
\text { light perception }\end{array}$ & $100 \%$ & $\begin{array}{c}4 \mathrm{~b} \\
\text { (blindness) }\end{array}$ \\
\hline
\end{tabular}

\section{RESULTS AND OBSERVATION}

Total 367 patients visited M \& J Institute of Ophthalmology for blindness certification during our study period, 311 were found eligible and were included in the study. Category of visual disability was classified according to guidelines of the Ministry of Social Justice and Empowerment, Government of India [Table l].

The age of the individuals ranged from 4 years to 91 years. Maximum of certified visually disabled individuals are in the age group of $21-30$ years $(73,23.47 \%)$. Children and young adults up to the age of 30 years constituted $150(48.23 \%)$ of cases. Among certified visually disabled individuals $212(68.17 \%)$ were males and 99(31.83\%) were females.

Retinitis Pigmentosa was the most common cause of visual disabled certification seen in $67(21.54 \%)$ cases. Out of these 67 individuals 39(12.54\%) were males and 28(9.00\%) were females. Also it was the most common cause seen with the $100 \%$ disability certification comprising of $60(23.25 \%)$ individuals out of 258 .

Second most common cause of disabled certification was the congenital ocular malformation comprising of $51(16.40 \%)$ individuals. Out of these 51 individuals 30(9.65) were males and $21(6.75 \%)$ were females.

Other major causes include optic atrophy(43 individuals, $13.83 \%)$, phthisis bulbi(27 individuals, $8.68 \%)$, corneal opacities(26 individuals, $8.36 \%$ ), glaucoma(21 individuals, $6.75 \%)$.

\section{DISCUSSION}

There have been many surveys in abroad and India regarding the prevalence of blindness in the community. They provide important information related to the causes of blindness and help the health planners to put strategies to decrease the prevalence of blindness. Evidence-based information is important to plan low vision care and rehabilitation services. Obtaining a visual handicap certificate is a part of rehabilitation of a blind person. It helps the blind person to obtain travel and income tax benefit. Data collected in this study may be useful to the governmental agencies to plan the strategies for rehabilitation and prevention. The study followed the criteria set by the Ministry of Social Justice and Empowerment for complete blindness.

In our study 311 patients were included among them 212 were males and 99 were females. This high ratio of male to female could be attributed to the increased outdoor activities of males or males may have more need for certification.

Patients in the age group of $11-40$ years and $41-70$ years were 
significantly large in number as compared to age above 70 years group. This suggests that the driving force behind attending any board for the disability certification was more among the working age group. This was probably due to the presence of certain benefits which were associated with the disability certification such as employment, education and conveyance, which was more likely to serve the purpose of young individuals than the elderly. Similar observations were made in Bunce et al(1998) study, where non-certification was found to be more common in patients of 65 years or more than those under 65 years, with a trend of increasing odds with increasing age ${ }^{6}$.

Also this study indicated there were 77 individuals (24.76\%) within the age group of 0-20 years. According to our study, diseases that caused permanent blindness in this age group include retinitis pigmentosa, congenital ocular anomalies, optic atrophy, phthisis bulbi, corneal opacity, amblyopia following uncorrected refractive errors, congenital cataract and related surgical complications, hereditary disease like albinism, retinopathy of prematurity, uveitis. Preventable causes of childhood blindness include corneal scarring due to vit A deficiency, measles, ophthalmia neonatorum, traditional practices, infective corneal ulcers; Intrauterine factors that include rubella, toxoplasmosis, other teratogens; perinatal factors including ROP, birth hypoxia; hereditary diseases. Treatable causes include cataract, glaucoma, ROP, uveitis, corneal disease (corneal ulcers and opacity). In 1997 according to WHO the numbers of blind children was 1.4 million. It was estimated that $45 \%$ of blind children were blind from avoidable causes. Thus prevention and treatment of childhood blindness is a necessity and priority to prevent significant effect of blindness on the physical, mental, and social development of a child.

In our study retinitis pigmentosa (67 individuals $21 \%$ ) was the leading cause of obtaining visual handicap certificate in our study. This finding correlated with the study Joshi et al (2008) in which they have accounted $15.05 \%$ of all disability ${ }^{7}$. This could be related to the increased consanguinity and lack of genetic counselling in the area.

Preventable blindness like, corneal opacities (8.36\%), glaucoma (6.57\%), amblyopia due to refractive errors (3.54\%), congenital cataract and surgery related complications (2.25\%) constituted the major causes of blindness certificate issued in our study. Early diagnosis and management of these diseases can prevent blindness arising due to these conditions. Facilities for the diagnosis and management of these entities must be made available in the rural areas of the district. Out of all the preventable causes' most cost effective outcome can be expected in cases with blindness due to refractive errors. Early intervention and proper treatment can prevent the blindness in these conditions in almost $100 \%$ of cases. These include conducting regular school camps, creating awareness among parents and children regarding regular and proper usage of spectacles and yearly check-up with an ophthalmologist.

\section{CONCLUSION}

The common causes of blindness can be decreased by improving public education and genetic counselling regarding common and preventable causes of blindness, as early diagnosis, treatment and visual rehabilitation can help to improve visual outcome and ultimately visual handicap in the society for the better future.

\section{REFERENCES}

1. World Health Organization. International statistical classification of diseases, injuries and causes of death, tenth revision. Geneva, 1993

2. World Health Organization, Global Data on Visual Impairments 2010, 2012

3. WHO, visual impairment and blindness fact sheet, no 282, June 2013, last updated October 2017.
4. K. Park. Epidemiology of Chronic Non-communicable diseases and Conditions. Park's Textbook of PREVENTIVE AND SOCIAL MEDICINE. 23rd edition, BHANAUT, 2015. Pp 263-413

5. Census of India, 2011.Ministry of Home Affairs,Government of India. Available from:

http://www.censusindia.gov.in/201 l census/population_enumeration.html

6. Bunce C, Evans J, Fraser S, Wormald R. The BD8 certification of visually impaired people. BrJOphthalmol 1998:82(1):72-76.5

7. Joshi RS. Causes of visual handicap amongst patients attending outpatien department of a medical college for visual handicap certification in central India. Journal of Clinical Ophthalmology and Research 2013;1 (1):17-19 